Hydrology and Earth System Sciences, 3(2), 177-185 (1999) @ EGS

\title{
A differentiation method for separating a mixture of suspended particle size distributions
}

\author{
H. Q. Wang, J. P. Dupont, R. Lafite and R. Meyer \\ Departement de Geologie Universite de Rouen UPRES A-CNRS 614376821 Mont-Saint-Aignan Cedex, France \\ e-mail of corresponding author: Huaqing.Wang@univ-rouen.fr
}

\section{Abstract}

A simple method is proposed to partition a mixture of two populations in suspended particle size data. The method, termed here 'the differentiation method' is based on the function of the lognormal distribution. Suspended material in marine or estuarine situations often consists of difficult-to-interpret complex populations. The treatment of particle size data by the method described enables the confirmation of the lognormal law and also the demonstration of the occurrence of a combination of a number of populations which may not be distinguished by the classical Gaussian transformation or automatic methods. A simple combination of graphical and numerical techniques permits the decomposition and the easy determination of the various statistical parameters (median diameter, mean diameter, etc . . .). The method is applied to interpret observed size distributions of suspended particulate matter in the Seine estuary. The method enables the determination of the relative sizes of the constituent sub-populations that comprise the total suspended matter. In the example used to illustrate the method, particles are shown to be resuspended as a function of different hydrodynamic parameters.

\section{Introduction}

Dupont et al. (1995) presented two particle size distribution data of suspended material in the Seine estuary at Honfleur (France). This site is located within the saline limit and the maximum turbidity zone of the estuary (Avoine, 1981). These two samples were obtained on $1 / 8 / 94$ from the surface waters in a period of flood of the Seine. One sample followed high water $(\mathrm{SC1}$, salinity $=$ $5.1 \mathrm{~g} / \mathrm{l})$ and the other taken at low water $(\mathrm{SC} 5$, salinity = $0.3 \mathrm{~g} / \mathrm{l}$ ) (Dupont et al., 1995). The particle size data were obtained by means of the Coulter counter which can be considered as a standard grain-size instrument in estuarine environment (Kranck, 1980; Eisma, 1986; Dupont et al., 1986; Eisma, 1993; Van Leussen, 1994). Collected samples were not treated and measurements were done in the daytime, keeping samples in the dark, as recommended by Lafite (1990).

The particle size distributions obtained are given in Fig. 1. At high water, the distribution is quite regular and appears unimodal, lognormal about a mode of $5 \mu \mathrm{m}$. According to Dupont et al. (1995), this population is comparable with that of the secondary population defined for upstream locations obtained on the same day. The sample taken at low water reveals a notable increase in particle concentration with a similarly regular unimodal lognormal distribution around a mode of $8 \mu \mathrm{m}$. This is smaller than the main population (mode of $10-11 \mu \mathrm{m}$ ) at the upstream sites cited previously (Dupont et al., 1995). The above measurements may signify that, at low water, the particle concentration is a mix of material remaining in suspension throughout the period of high water and of material resuspended as the tide ebbs. Thus, these two types of material have different hydrodynamic regimes.

This mixture of particle populations from different hydrodynamic regimes may also be defined qualitatively by means of the scanning electron microscope. Microflocs are the main components of these two populations, sticking of elemental particles is mainly due to organic matter. Unflocculated fine-grained have been observed in suspension only in iced environment where organic matter content is very low (Syvitski and Murray, 1981). In estuaries, macroflocs, upper $100 \mu \mathrm{m}$, break up during sampling into smaller flocs (Eisma, 1993).

Study of particle settling velocities (Fig. 2) confirms further the presence of the mixed populations of two different hydrodynamic components. According to the results obtained by Dupont et al. (1995), the microfloc settling velocities are described by a power function of diameter $D$ as $\omega_{s}=K * D^{n}$ which is characterized by a straight line in a $\log$-log paper. From Fig. 2, the points of the particle settling velocities lie on a straight line for SC1 and present two intersecting straight lines with different slopes for SC5. 


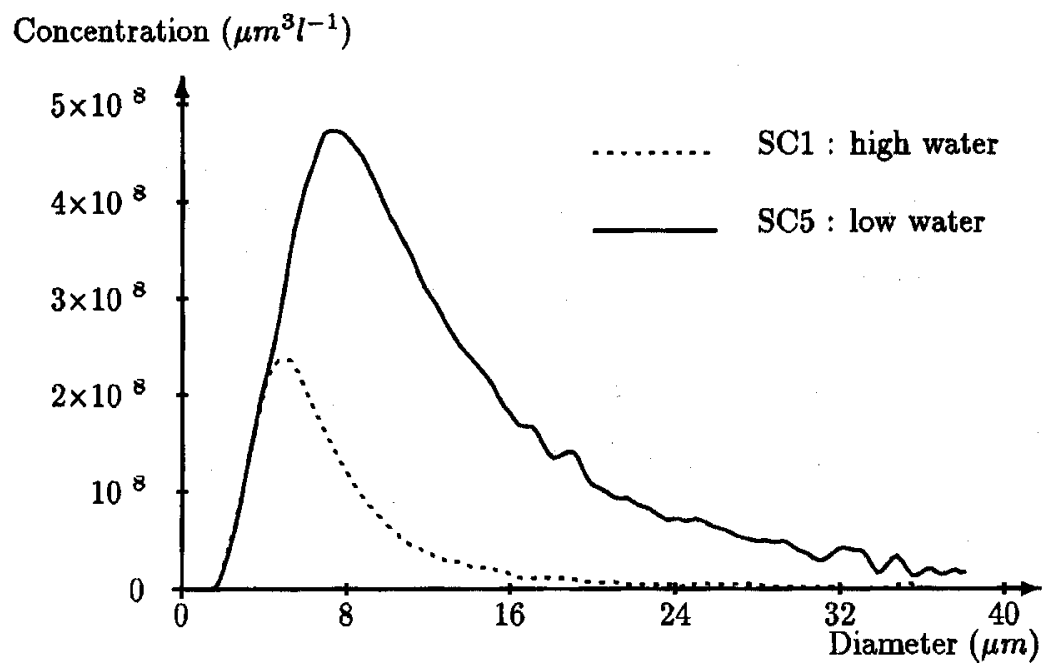

Fig. 1. Comparison of two sets of particle size distribution data (SCI at high water, SC5 at low water) obtained at Honfleur (Seine estuary, France).

How may these mixed particle populations be distinguished? In the literature, there are two basic approaches to solving this problem. One is a graphical technique (Harding, 1949; Tennant and White, 1959; Sinclair, 1974) and the other is a numerical (or 'automatic') process (Clark, 1977). The graphical method is based on Gaussian transformation (or the use of probability papers). The numerical method uses an optimization or least-squares process. A combined method of graphical and numerical approaches has been proposed (McCammon, 1976a, 1976b; Bridges and McCammon, 1980). These two basic approaches have been applied to decompose the mixed particle populations of SC5. Figure 3 shows the results of Gaussian transformation of SC5 data. 'Inverfc' is the inverse of the complementary error function. If the data studied have a normal or lognormal distribution, a straight line is obtained on Inverfc-D (or $\log \mathrm{D}$ ) diagram. When a mixed distribution exists, the Inverfc-D (or $\log \mathrm{D}$ ) data present a variable slope. Figure 3 shows one straight line only for the Inverfc-logD data of SC5. Hence, this graphical method is unable to decompose the mixture of two sub-populations defined by the scanning electron microscope and also by analysis of the hydrodynamic context. Figure 4 presents the final best fit of the particle size data of SC5 with two lognormal distribution functions by using the nonlinear least-squares decomposition method (Clark, 1977). The particle size data are well adjusted. However, the two components (with means of about 11

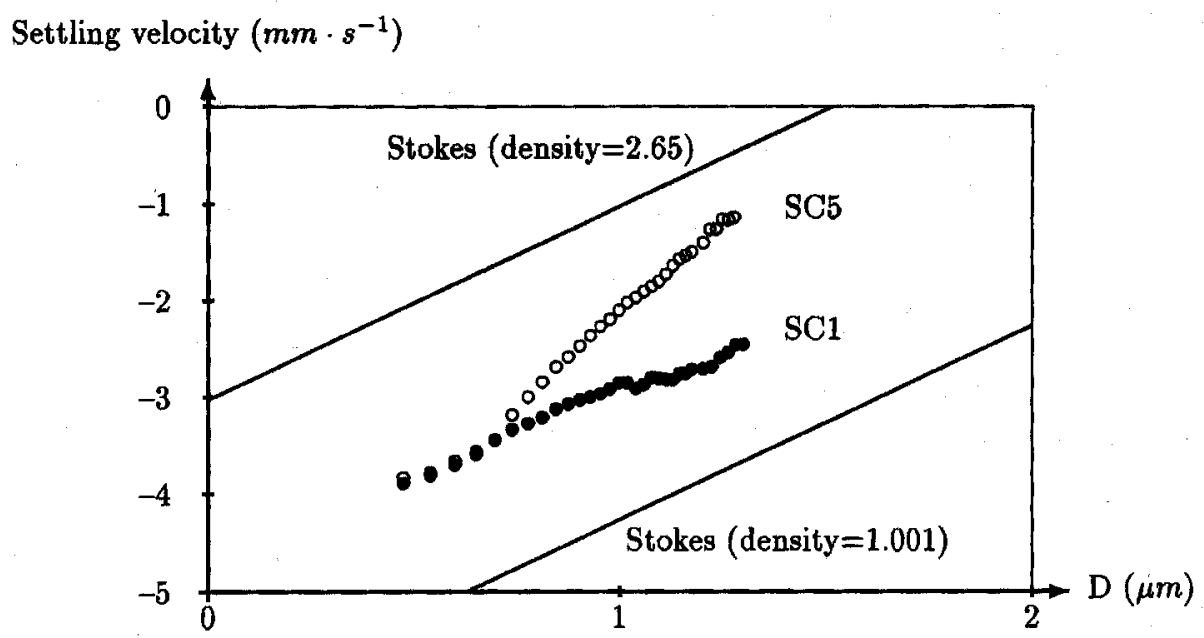

Fig. 2. Comparison of the particle settling velocities for the two sets of particle size distribution data (SC1 at high mater, SC5 at lom mater) presented in Fig. 1. 


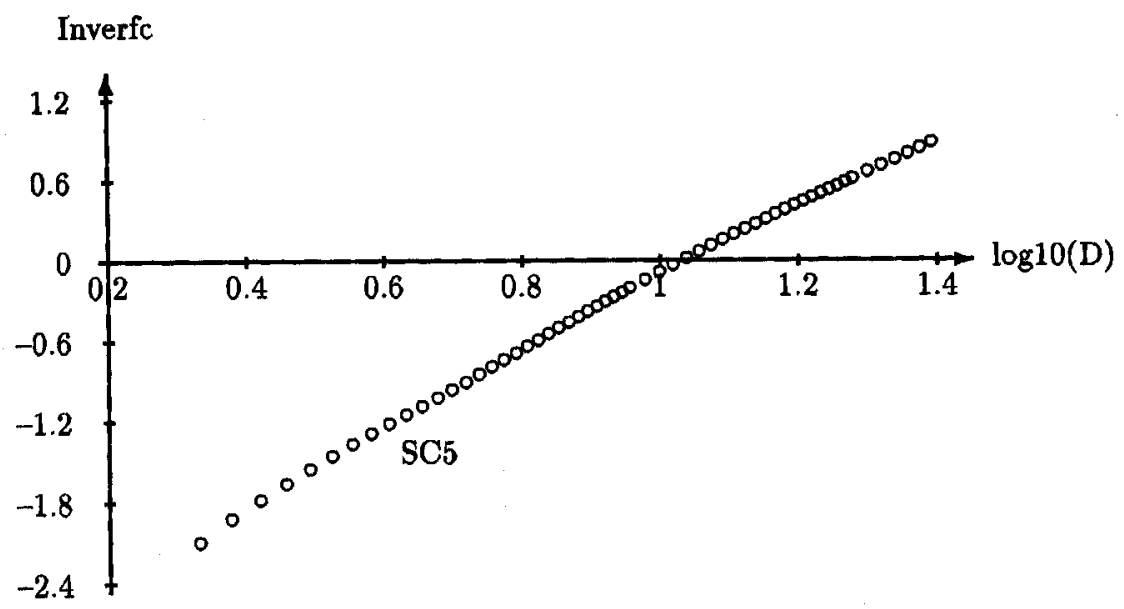

Fig. 3. Gaussian transformation of the particle size distribution data (SC5 at low water).

and $28 \mu \mathrm{m}$ respectively) obtained by this automatic method are very different from those observed by the scanning electron microscope (with means of about 6 and $14 \mu \mathrm{m}$ respectively). In fact, the secondary component obtained presents data relating to coarser particle size classes which are poorly represented here.

The following sections present a new method for separating a mixture of two lognormal distributions using derivative frequency data. Following an explanation of the principle of the method, it is applied to the interpretation of the particle size data cited above. The method enables the decomposition of these mixed particle populations for SC5.

\section{The differentiation method}

The particle size distribution of concentrations of suspended material is often considered to reflect a simple lognormal law or the summation of a number of such laws (Lambert et al., 1981; Brun-Cottan, 1977, 1986; Dupont $e t$ al., 1986; Dupont et al., 1995). The frequency of occurrence of particles by this lognormal law is given by:

$$
\phi=\frac{1}{\sqrt{2 \pi \sigma^{2}} D} \cdot \exp \left(-\frac{(\ln D-\mu)^{2}}{2 \sigma^{2}}\right)
$$

where $D$ : particle equivalent diameter;

$\phi$ : frequency;

$\mu$ : mid-point coefficient (or median in $\ln D$ );

$\sigma^{2}$ : dispersion coefficient (or variance in $\ln D$ ).

The value of $\phi$ may be calculated by:

$$
\phi=\frac{V}{V_{T} \cdot \Delta D}
$$

and $V:$ concentration of a given size class;

$V_{T}$ : sum of concentrations of all size classes considered;

$\Delta D$ : size class intervals.
By knowing the values of $\mu$ and $\sigma^{2}$ and by using the following formulae, the statistical parameters of the particle distribution may be calculated (Brun-Cottan, 1986; Saporta, 1990):

$$
\left.\begin{array}{l}
D_{\text {mod }}=\exp \left(\mu-\sigma^{2}\right) \\
D_{\text {med }}=\exp (\mu) \\
D_{m n}=\exp \left(\mu+\sigma^{2} / 2\right) \\
V a r=\exp \left(2 \mu+\sigma^{2}\right) \cdot\left(\exp \left(\sigma^{2}\right)-1\right)
\end{array}\right\}
$$

where $D_{\text {mod: }}$ modal diameter;

$D_{\text {med: }}$ median diameter;

$D_{m n}: \quad$ mean diameter;

Var: variance of diameter.

From the formulae (3), it is evident that the value of the median diameter lies between the values for the modal diameter and the mean diameter. Equation (1) is the basis of the differentiation method.

\section{PRINCIPLE OF THE METHOD}

The Naperian logarithm of Eqn. (1) is written:

$$
\ln \phi=\ln \left(\frac{1}{\sqrt{2 \pi \sigma^{2}}}\right)-\ln D-\frac{1}{2 \sigma^{2}} \cdot(\ln D-\mu)^{2}
$$

Let:

$$
Y=\ln \phi \quad \text { and } \quad X=\ln D
$$

Eqn. (4) becomes:

$$
Y=\ln \left(\frac{1}{\sqrt{2 \pi \sigma^{2}}}\right)-X-\frac{1}{2 \sigma^{2}} \cdot(X-\mu)^{2}
$$

Differentiating $Y$ with respect to $X$, gives:

$$
Y^{\prime}=\left(\frac{\mu}{\sigma^{2}}-1\right)-\frac{1}{\sigma^{2}} \cdot X
$$


or, in general terms:

$$
Y^{\prime}=a+b \cdot X
$$

where:

$$
a=\frac{\mu}{\sigma^{2}}-1 \quad \text { and } \quad b=-\frac{1}{\sigma^{2}}
$$

$Y^{\prime}$ and $X$ are therefore connected by a simple relationship; the equation of a straight line.

The values of $a$ and $b$ may be determinated by particle size data, which is presented later. According to Eqn. (9), the parameters $\mu$ and $\sigma^{2}$ may be obtained easily using the following formulae:

$$
\mu=-\frac{a+1}{b} \quad \text { and } \quad \sigma^{2}=-\frac{1}{b}
$$

From Eqn. (3), the statistical parameters $D_{m o d}, D_{m e d}, D_{m n}$ and $V a r$ may finally be calculated:

$$
\left.\begin{array}{l}
D_{\text {mod }}=\exp \left(-\frac{a}{b}\right) \\
D_{\text {med }}=\exp \left(-\frac{a+1}{b}\right) \\
D_{m n}=\exp \left(-\frac{a+1.5}{b}\right) \\
V a r=\exp \left(-\frac{2 a+3}{b}\right) \cdot\left(\exp \left(-\frac{1}{b}\right)-1\right)
\end{array}\right\}
$$

\section{DISCRETIZATION FORMULA}

The aim is to calculate the values of $X$ and $Y^{\prime}$ on the basis of particle size data consisting of couples $\left(D_{i}, \phi_{i}\right)$. If two pairs of values, $\left(D_{i}, \phi_{i}\right)$ and $\left.\left(D_{i+1}\right), \phi_{i+1}\right)$ are considered, from Eqn. (4):

$$
\left(\frac{\ln \phi_{i+1}-\ln \phi_{i}}{\ln D_{i+1}-\ln D_{i}}\right)=-\frac{1}{\sigma^{2}} \cdot\left(\frac{\ln D_{i+1}+\ln D_{i}}{2}\right)+\frac{\mu}{\sigma^{2}}-1
$$

or equally, $Y_{i+1 / 2}^{r}=a+b \cdot X_{i+1 / 2}$, with:

$$
X_{i+1 / 2} \approx \frac{\ln D_{i+1}+\ln D_{i}}{2} \quad \text { and } \quad Y_{i+1 / 2}^{\prime} \approx \frac{\ln \phi_{i+1}-\ln \phi_{i}}{\ln D_{i+1}-\ln D_{i}}
$$

Table 1 demonstrates an example of calculation of $X_{i+1 / 2}$ and $Y_{i+1 / 2}^{\prime}$.

Other discretization formula may be used if a greater precision of calculation is required. Precision will increase as class interval size is reduced.

\section{DETERMINATION OF THE COEFFICIENTS $a$ AND $b$}

The relationship between $Y^{\prime}$ and $X$ is affine. Linear

\begin{tabular}{|c|c|c|c|c|c|}
\hline No & $D_{i}(\mu m)$ & $V_{i}\left(\mu m^{3} t^{-1}\right)$ & pair & $X_{i}$ & $Y_{i}^{\prime}$ \\
\hline 1 & 2.14 & $2.96 \cdot 10^{7}$ & - & - & - \\
\hline 2 & 2.38 & $4.78 \cdot 10^{7}$ & $1-2$ & 0.81 & 4.51 \\
\hline 3 & 2.62 & $6.69 \cdot 10^{7}$ & $2-3$ & 0.92 & 3.50 \\
\hline 4 & 2.86 & $8.99 \cdot 10^{7}$ & $3-4$ & 1.01 & 3.37 \\
\hline 5 & 3.09 & $1.14 \cdot 10^{8}$ & $4-5$ & 1.09 & 3.07 \\
\hline 6 & 3.33 & $1.39 \cdot 10^{8}$ & $5-6$ & 1.17 & 2.65 \\
\hline 7 & 3.57 & $1.64 \cdot 10^{8}$ & $6-7$ & 1.24 & 2.38 \\
\hline 8 & 3.81 & $1.87 \cdot 10^{8}$ & $7-8$ & 1.31 & 2.04 \\
\hline 9 & 4.05 & $2.08 \cdot 10^{8}$ & $8-9$ & 1.37 & 1.72 \\
\hline 10 & 4.28 & $2.23 \cdot 10^{8}$ & $9-10$ & 1.43 & 1.26 \\
\hline 11 & 4.52 & $2.32 \cdot 10^{8}$ & $10-11$ & 1.48 & 0.71 \\
\hline 12 & 4.76 & $2.36 \cdot 10^{8}$ & $11-12$ & 1.53 & 0.34 \\
\hline 13 & 5.00 & $2.37 \cdot 10^{8}$ & $12-13$ & 1.58 & 0.08 \\
\hline 14 & 5.24 & $2.36 \cdot 10^{8}$ & $13-14$ & 1.63 & -0.09 \\
\hline 15 & 5.47 & $2.30 \cdot 10^{8}$ & $14-15$ & 1.68 & -0.57 \\
\hline 16 & 5.71 & $2.20 \cdot 10^{8}$ & $15-16$ & 1.72 & -1.06 \\
\hline 17 & 5.95 & $2.08 \cdot 10^{8}$ & $16-17$ & 1.76 & -1.36 \\
\hline 18 & 6.19 & $1.96 \cdot 10^{8}$ & $17-18$ & 1.80 & -1.50 \\
\hline 19 & 6.43 & $1.84 \cdot 10^{8}$ & $18-19$ & 1.84 & -1.66 \\
\hline 20 & 6.67 & $1.73 \cdot 10^{8}$ & $19-20$ & 1.88 & -1.63 \\
\hline 21 & 6.90 & $1.64 \cdot 10^{8}$ & $20-21$ & 1.91 & -1.63 \\
\hline 22 & 7.14 & $1.54 \cdot 10^{8}$ & $21-22$ & 1.95 & -1.84 \\
\hline 23 & 7.38 & $1.44 \cdot 10^{8}$ & $22-23$ & 1.98 & -2.01 \\
\hline 24 & 7.62 & $1.34 \cdot 10^{8}$ & $23-24$ & 2.01 & -2.25 \\
\hline 25 & 7.86 & $1.25 \cdot 10^{8}$ & $24-25$ & 2.05 & -2.38 \\
\hline 26 & 8.09 & $1.17 \cdot 10^{8}$ & $25-26$ & 2.08 & -2.18 \\
\hline 27 & 8.33 & $1.09 \cdot 10^{8}$ & $26-27$ & 2.11 & -2.44 \\
\hline 28 & 8.57 & $1.01 \cdot 10^{8}$ & $27-28$ & 2.13 & -2.66 \\
\hline 29 & 8.81 & $9.40 \cdot 10^{7}$ & $28-29$ & 2.16 & -2.60 \\
\hline 30 & 9.05 & $8.81 \cdot 10^{7}$ & $29-30$ & 2.19 & -2.41 \\
\hline 31 & 9.28 & $8.23 \cdot 10^{7}$ & $30-31$ & 2.22 & -2.71 \\
\hline 32 & 9.52 & $7.71 \cdot 10^{7}$ & $31-32$ & 2.24 & -2.56 \\
\hline 33 & 9.76 & $7.21 \cdot 10^{7}$ & $32-33$ & 2.27 & -2.71 \\
\hline 34 & 10.0 & $6.70 \cdot 10^{7}$ & $33-34$ & 2.29 & -2.98 \\
\hline 35 & 10.2 & $6.16 \cdot 10^{7}$ & $34-35$ & 2.31 & -3.56 \\
\hline 36 & 10.5 & $5.74 \cdot 10^{7}$ & $35-36$ & 2.34 & -3.18 \\
\hline 37 & 10.7 & $5.30 \cdot 10^{7}$ & $36-37$ & 2.36 & -3.49 \\
\hline 38 & 10.9 & $4.87 \cdot 10^{7}$ & $37-38$ & 2.38 & -3.85 \\
\hline 39 & 11.2 & $4.54 \cdot 10^{7}$ & $38-39$ & 2.40 & -3.26 \\
\hline
\end{tabular}
regression analysis may therefore be used to determine coefficients $a$ and $b$, i.e.:

$$
b=\frac{\Sigma\left(X_{i}-\bar{X}\right)\left(Y_{i}^{\prime}-\bar{Y}^{\prime}\right)}{\Sigma\left(X_{i}-\bar{X}\right)^{2}} \quad \text { and } \quad a=\bar{Y}^{\prime}-b \cdot \bar{X}
$$

where:
Table 1. Example of calculation of $X_{i}$ and $Y_{i}^{\prime}$ data-particle size data (SC1) obtained from the Seine estuary (Honfleur, France).

$$
\bar{X}=\frac{\Sigma X_{i}}{N} \text { and } \quad \bar{Y}^{\prime}=\frac{\Sigma Y_{i}^{\prime}}{N}
$$

The correlation coefficient $r$ between $X_{i}$ and $Y_{i}^{\prime}$ is given by:

$$
r=\frac{\Sigma\left(X_{i}-\bar{X}\right)\left(Y_{i}^{\prime}-\bar{Y}^{\prime}\right)}{\sqrt{\Sigma\left(X_{i}-\bar{X}\right)^{2} \cdot \Sigma\left(Y_{i}^{\prime}-\overline{Y^{\prime}}\right)^{2}}}
$$




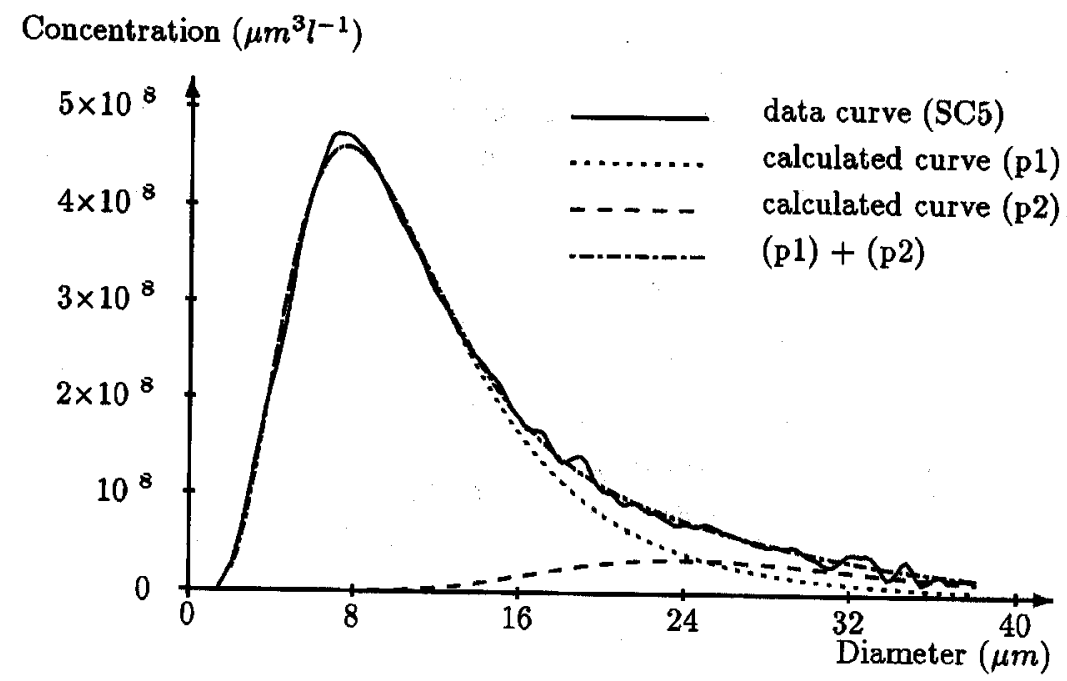

Fig. 4. Best fitting of decomposition of the particle size distribution data (SC5 at low water) using nonlinear least-squares method.

The results obtained from Eqns. (14) and (15) may be influenced strongly by singular data relating to coarser particle size classes. This may also occur in the case of a mixture of two populations where the $X_{i}$ and $Y_{i}^{\prime}$ ordinates cannot be well represented by a single line of best fit. It is, therefore, preferable to employ a combination of numerical and graphical techniques that permits the elimination of singular data and the use of selected data only for determining the parameters $a$ and $b$. To apply this method graphically, it is necessary only to transfer the values of $X_{i}$ and $Y_{i}^{\prime}$ to graph paper and to draw the line that conforms to the greatest possible number of points. By taking any two points on this line $\left(X_{1}, Y_{1}^{\prime}\right)$ and $\left(X_{2}, Y_{2}^{\prime}\right)$ are obtained and thus:

$$
b=\frac{Y_{2}^{\prime}-Y_{1}^{\prime}}{X_{2}-X_{1}} \quad \text { and } \quad a=Y_{1}^{\prime}-b \cdot X_{1}
$$

With the values of $a$ and $b$, it is easy to calculate $\mu$ and $\sigma_{2}$ from Eqn. (10) and determine the statistical parameters $D_{m o d}, D_{m e d}, D_{m n}$ and Var by Eqn. (11).

\section{Validation of the method and discussion}

We shall demonstrate the validity of the differentiation method numerically and, using theoretical data calculated according to Eqn. (1), illustrated with $X_{i}-Y_{i}^{*}$ diagrams the occurrence of a mixture of two populations. Two cases are discussed.

\section{SINGLE POPULATION}

The numerical data used in this case are obtained by Eqn. (1) for $\mu=2.2$ and $\sigma_{2}=0.36$. The distribution curve is shown in Fig. 5a and the $X_{i}-\mathrm{Y}_{i}^{\prime}$ diagram produced by the differentiation method in Fig. 5b. In the diagram the $X_{i}-$ $Y_{i}^{\prime}$ ordinates are well aligned. The straight line drawn through the points enables the precise values of $\mu$ and $\sigma_{2}$ to be recalculated.

In the $X_{i}-\mathrm{Y}_{i}^{\prime}$ diagram the central parameters, $D_{\text {mod }}$, $D_{m e d}$ and $D_{m n}$ may be easily located. In effect, Eqn. (8) may be rewritten as

$$
X=-\frac{a-Y^{\prime}}{b}
$$

now, as $X=\ln D$,

$$
D=\exp \left(-\frac{a-Y^{\prime}}{b}\right)
$$

By comparing Eqns. (19) and (11), the central parameters $D_{m o d}, D_{m e d}$ and $D_{m n}$ are seen to be on the $X_{i}-Y_{i}^{\prime}$ diagram, the values of $X_{i}$ corresponding respectively to $Y_{i}^{\prime}$ values of $0,-1$ and -1.5 (see Fig. $5 b$ ).

\section{MIXTURE OF TWO POPULATIONS}

Here, two distinct cases are highlighted: (i) a mixture of two populations of which the central parameters are quite different and (ii) a mixture of two populations of which the central parameters are quite similar. In the first case, the mixed distribution curve appears bimodal and the mixture is considered 'visible'. The second case is considered 'invisible' as the function of distribution appears unimodal: the occurrence of a mixture of two populations is not discernible.

Table 2 gives the parameters used for the two conditions studied.

The distribution curves of these populations and their sub-populations are presented in Figs. 6a and 7a. The corresponding diagrams produced by the differentiation method are shown in Figs. $6 \mathrm{~b}$ and $7 \mathrm{~b}$. 

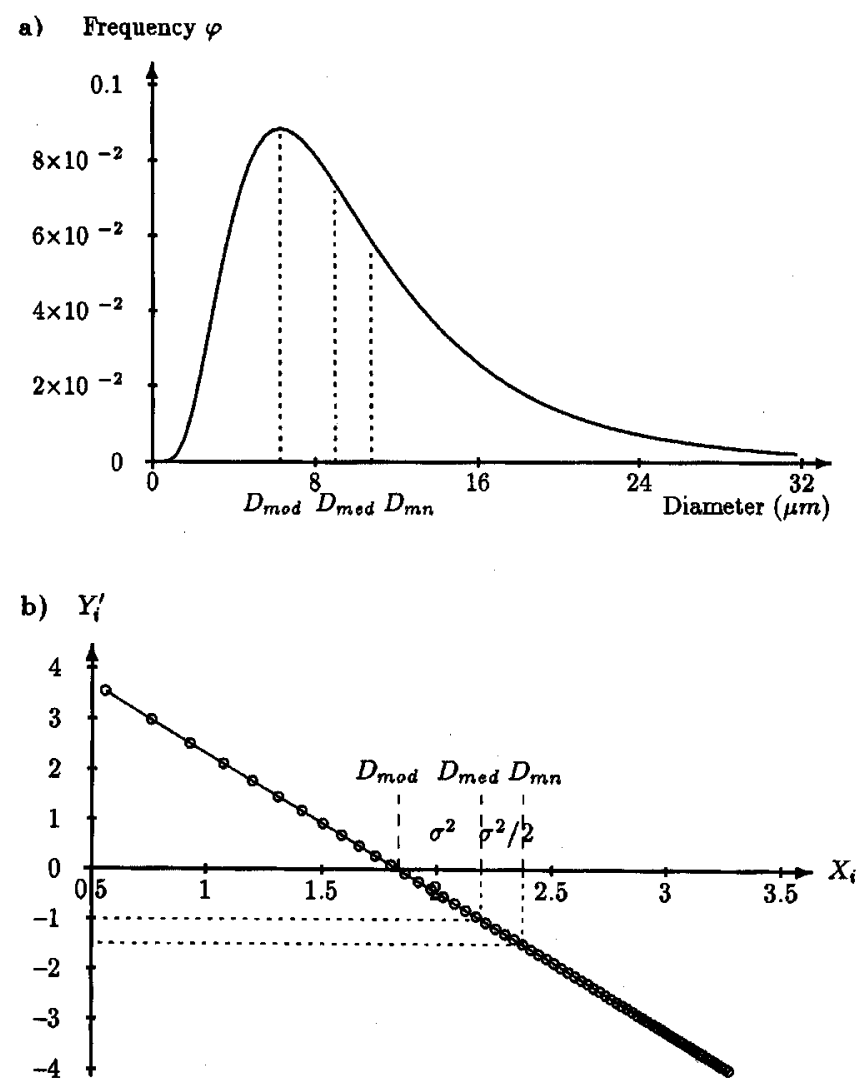

Fig. 5. Proof of the differentiation method using theoretical data: a) lognormal distribution curve; b) $X_{i}-Y_{i}^{\prime}$ diagram produced by the differentiation method.

For the two cases, each $X_{i}-\mathrm{Y}_{i}^{\prime}$ diagram has generated two straight lines, the first representing population 1 and the second representing population 2 . The slopes reflect the characteristics of the two constituent sub-populations comprising the whole. The region lying between the two straight lines represents a zone of mixing with variable slope.

Table 2. Hypothetical statistical parameters used to illustrate the different cases of mixed lognormal populations discussed.

1) 'visible' mixture:

\begin{tabular}{lllr}
\hline parameters & $\mu$ & $\sigma^{2}$ & $D_{\text {med }}$ \\
population 1 & 1.61 & 0.16 & 5.0 \\
population 2 & 2.48 & 0.16 & 12.0 \\
\hline
\end{tabular}

2) 'invisible' mixture:

\begin{tabular}{llll}
\hline parameters & $\mu$ & $\sigma^{2}$ & $D_{\text {med }}$ \\
population 1 & 1.61 & 0.16 & 5.0 \\
population 2 & 2.20 & 0.16 & 9.0 \\
\hline
\end{tabular}

Two straight lines produced by the differentiation method shown above enable the separation of the two subpopulations comprising the mixture and the recovery of the statistical parameters corresponding to each. Application of the differentiation method is most valuable in the second case studied, where the function of distribution is unimodal ('invisible' mixture). The $X_{i}-Y_{i}^{\prime}$ diagram brings to light the occurrence of this 'invisible' mixture.

\section{Application to particle size distribu- tion data in the Seine estuary}

Grain-size analysis evolution has been demonstrated during tidal cycle in estuaries such as the Elbe (Chen et al., 1994), the Rhine (Eisma et al., 1980) and the Dollard (Eisma and Li, 1993). Annual evolution of grain-size distribution has been found in the lower Seine estuary (Lafite, 1990). The differentiation method permits identification and quantification of two particle size distribution data of suspended material collected in the entire Seine estuary, from fresh to marine water. The previous finding of a mix of two populations for SC5 is confirmed by the
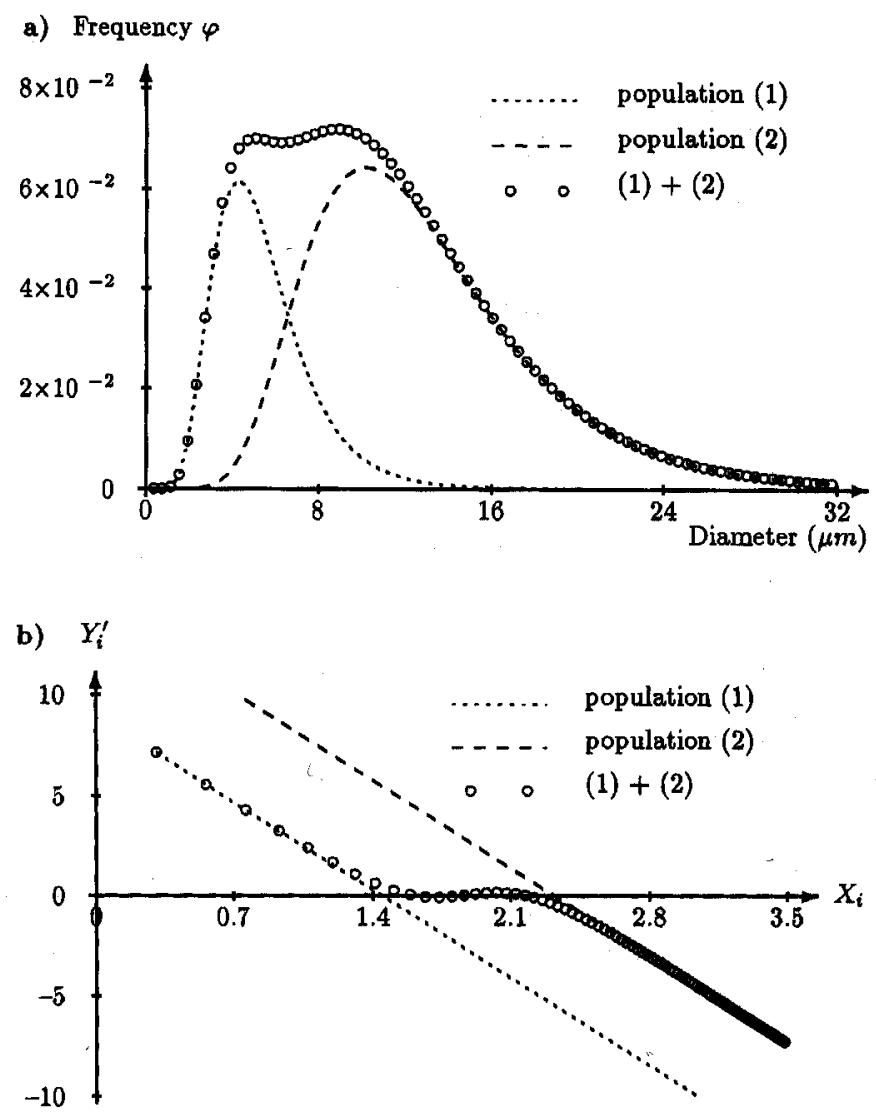

Fig. 6. Illustration of the occurrence of a mixture of two lognormal populations-'visible' mixture: a) lognormal distribution curves; $b$ ) $X_{i}-Y_{i}^{\prime}$ diagram produced by the differentiation method. 
a) Frequency $\varphi$

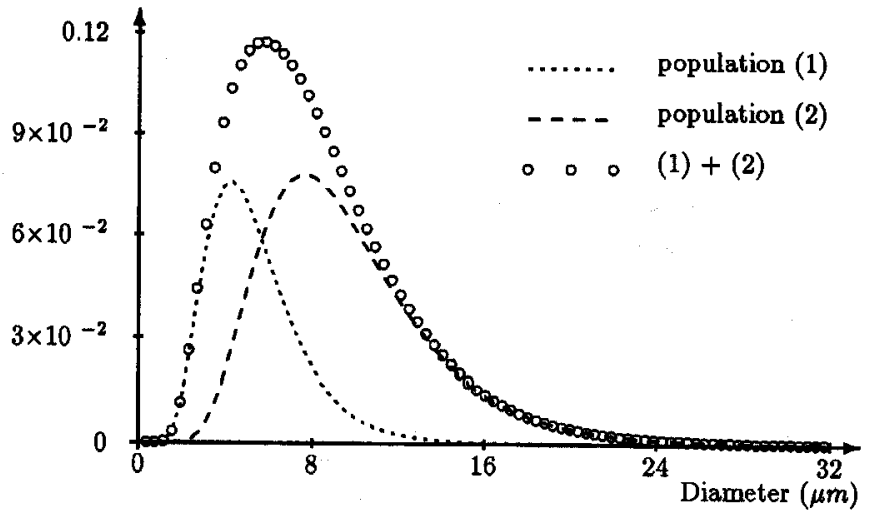

b) $Y_{i}^{\prime}$

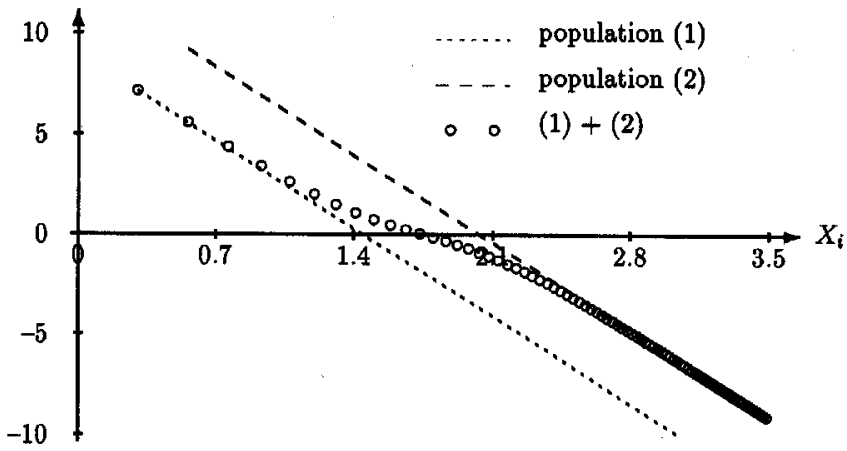

Fig. 7. Illustration of the occurrence of a mixture of two lognormal populations- 'invisible' mixture: a) lognormal distribution curves; $b$ ) $X_{i}-Y_{i}^{\prime}$ diagram produced by the differentiation method.

differentiation method's $X_{i}-\mathrm{Y}_{i}^{\prime}$ diagram for the particle size data (see Fig. 8). In Fig. 8, the values obtained for SC1 (high water) and SC5 (low water) produce contrasting slopes. For the smallest size ranges, the $X_{i}$ and $\mathrm{Y}_{i}^{\prime}$ ordinates for the two populations coincide. This confirms that

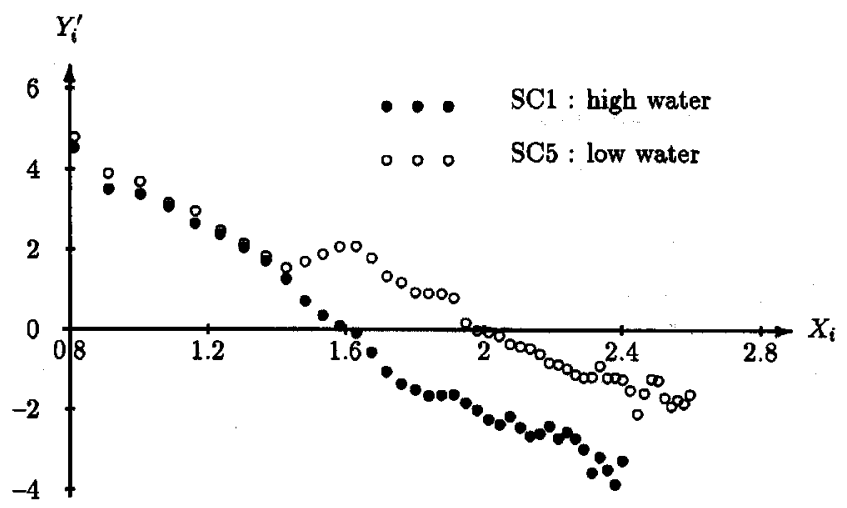

Fig. 8. Comparison of two sets of particle size data (SC1 at high water, SC5 at low water) $-X_{i}-Y_{i}^{\prime}$ diagram produced by the differentiation method. the SC5 data comprises two particle populations with different hydrodynamic origins and that one of these populations is practically identical to that of SC1.

Application of the differentiation method (see Figs. 9 and 10) enables the statistical parameters of these populations to be determined (Table 3). The distribution curves obtained by the method (Figs. $9 \mathrm{~b}$ and $10 \mathrm{~b}$ ) show a very good agreement with those actually observed for each of the two samples taken.

The statistical parameters of population 1 extracted from sample SC5 are very close to those of SC1 showing that the hydrodynamic origins of the two particle populations are practically identical. The same may be stated for population 2 (mode of $9.66 \mu \mathrm{m}$ ) extracted from SC5; this is very similar to the populations observed (modes of 10 and $11 \mu \mathrm{m}$ ) at sites further upstream (Dupont $e t$ al., 1995). Additionally, for SC5, the relative size of each sub-population comprising the sample, i.e. the quantity of continuously suspended matter and the quantity that is resuspended, is obtained.

In agreement with previously published data (Dupont $e t$ al., 1986; Lafite, 1991; Dupont et al., 1994; Eisma, 1993; Van Leussen, 1994), the characterization of particle populations from samples studied reveals qualitative differences. The separation method presented here allows

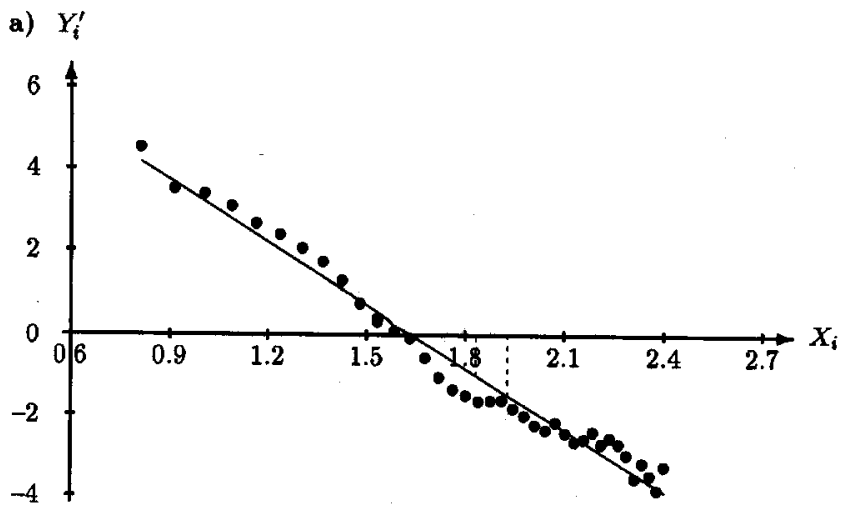

b) Concentration $\left(\mu m^{3} l^{-1}\right)$

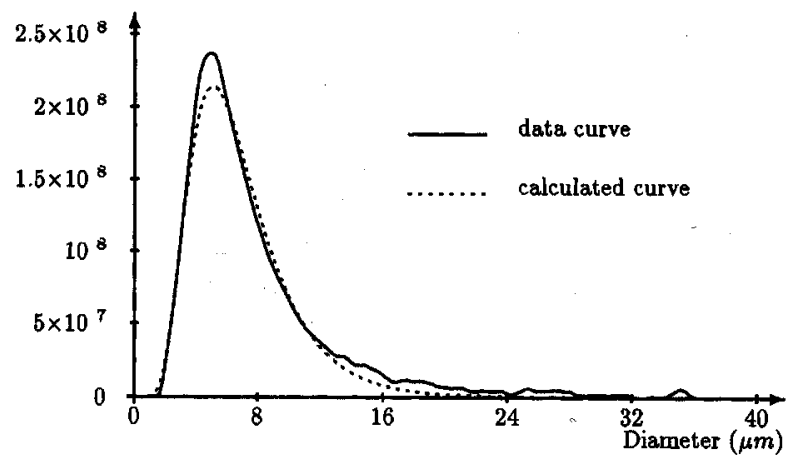

Fig. 9. Identification of lognormal statistical parameters of particle size distribution (SCI): a) $X_{i}-Y_{i}^{\prime}$ diagram produced by the differentiation method; $b$ ) comparison of observed and calculated particle size distributions. 
Table 3. Statistical parameters for population distributions (SC1 and SC5) calculated by the differentiation method.

\begin{tabular}{lccc}
\hline parameters & SC1 & \multicolumn{2}{c}{ SC5 } \\
\cline { 2 - 4 } & \multicolumn{3}{c}{ population 1 population 2 } \\
\hline$a$ & 8.29 & 8.74 & 9.32 \\
$b$ & -5.07 & -5.05 & -4.11 \\
$r$ correlation & & & \\
$\quad$ coefficient & -0.988 & -0.992 & -0.931 \\
$\mu$ & 1.83 & 1.93 & 2.51 \\
$\sigma^{2}$ & 0.197 & 0.198 & 0.243 \\
$D_{\text {mod }}(\mu m)$ & 5.13 & 5.64 & 9.66 \\
$D_{\text {med }}(\mu m)$ & 6.25 & 6.87 & 12.32 \\
$D_{\text {mn }}(\mu m)$ & 6.90 & 7.59 & 13.92 \\
$\operatorname{Var}\left(\mu m^{2}\right)$ & 10.37 & 12.60 & 53.36 \\
percentage of & & & \\
$\quad$ surface area $(\%)$ & 100 & 34.7 & 65.3 \\
\hline
\end{tabular}

quantitative calculation of the relative size of each particle sub-population where their composition is defined qualitatively by the scanning electron microscope and also by the study of particle settling velocities.

\section{Conclusion}

The differentiation method provides a simple graphical technique to confirm the occurrence of a lognormally distributed population. Applied to the particle size distribution of suspended material, it enables the determination of the statistical parameters of the population. In certain cases, the technique can signal the occurrence of a mixture of two populations of different origin and can assess the characteristics of these populations with some precision. The method is most useful in the case of an 'invisible' mixture having an apparently unimodal particle size distribution. This has been verified by applying the method to the interpretation of the real mixed particle size populations which cannot be separated by classical methods.

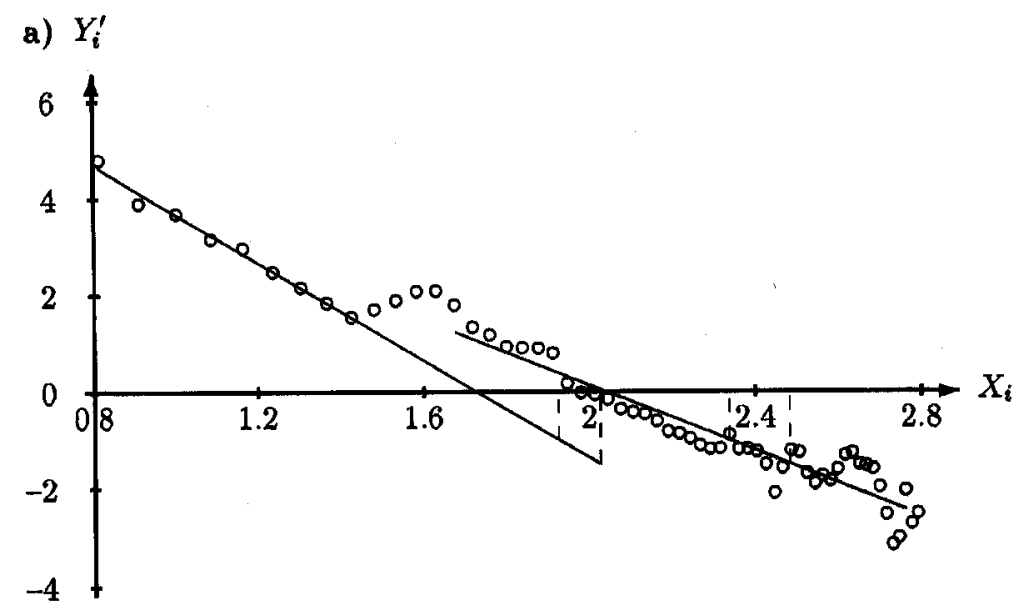

b) Concentration $\left(\mu m^{3} \eta^{-1}\right)$

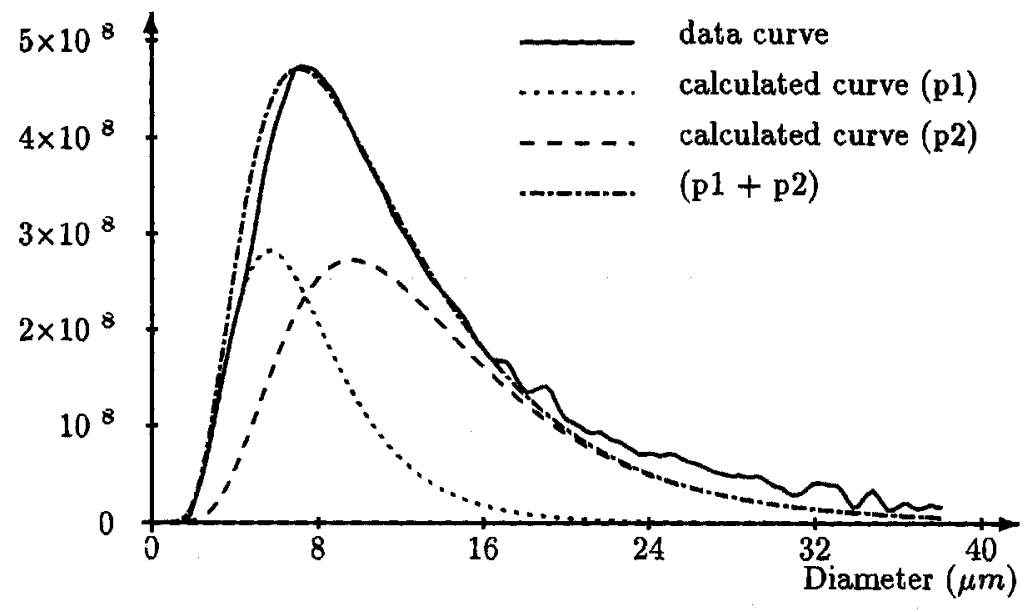

Fig. 10. Separation of data and identification of lognormal statistical parameters for particle size distribution (SC5): a) $X_{i}-Y_{i}^{\prime}$ diagramproduced by the differentiation method; $b$ ) comparison of observed and calculated particle size distributions. 


\section{References}

Avoine, J., 1981. L'estuaire de la Seine: Sédiments et dynamique sédimentaire, Thèse $3^{\text {me }}$ cycle, Université de Caen, 236pp.

Bridges, N. J. and McCammon, R. B., 1980. DISCRIM: A computer program using an interactive approach to dissect a mixture of normal or lognormal distributions. Computers $\mathbb{E}$ Geosci., 6, 361-396.

Brun-Cottan, J. C., 1977. Contribution à l'étude de la granulométrie et de la cinétique des particules marines. 7. Recherche Océanographique, 21, 41-54.

Brun-Cottan, J. C., 1986. Vertical transport of particles within the Ocean. In P. Buat-Ménard Ed., NATO-ASI, The Role of Air-Sea Exchange in Geochemical Cycling, Reidel, 83-111.

Chen, S., Eisma, D. and Kalf, J., 1994. In situ distribution of suspended matter during the tidal cycle in the Elbe estuary. Netherlands 7. Sea Res., 32, 37-48.

Clark, I., 1977. ROKE, A computer program for nonlinear leastsquares decomposition of mixtures of distributions. Computers \& Geosci., 3, 245-256.

Dupont, J.P., Lafite, R. and Lamboy, M., 1986. Contribution de l'étude des suspensions à la compréhension des mécanismes hydrosédimentaires estuaires et littoraux en Manche centrale et orientale, In: ' $L a$ Baie de Seine', IFREMER, Actes de Colloques, 4, 145-153.

Dupont, J.P., Lafite, R., Huault, M.F. and Meyer, R., 1994. Continental/marine ratio changes in suspended and settled matter across a macrotidal estury (the Seine estuary, northwestern France). Marine Geol., 120, pp 27-40.

Dupont, J.P., Wang, H.Q., Lafite, R., Meyer, R. and Texier, H. 1995. Granulométrie et vitesse de chute des matières en suspension en estuaire de Seine. C. R. Acad. Sciences, Paris, t.320, série IIa, 961-968.

Eisma, D., 1986. Flocculation and re-flocculation of suspended matter in Estuaries. Netherlands 7. Sea Res., 20, 183-199.

Eisma, D., 1993. Suspended matter in the aquatic environment. Springer Verlag: 315pp.

Eisma, D., Kalf J. and Veenhuis, M., 1980. The formation of small particles and aggregates in the Rhine estuary. Netherlands 7. Sea Res., 14, 172-191.
Eisma, D. and Li, A., 1993. Changes in suspended matter floc size during the tidal cycle in the Dollard estuary. Netherlands 7. Sea Res., 31, 107-117.

Harding, J. P., 1949. The use of probability paper for the graphical analysis of polymodal frequency distributions. 7. Marine Biol. Assn., 28, 141-154.

Kranck, K., 1980. Particulate matter grain-size characteristics and flocculation in a partially mixed estuary. Sedimentology, 28: 107-114.

Lafite, R., 1990. Caractérisation et dynamique des particules en suspension dans un domaine marin macrotidal influencé par un estuaire: l'exemple de la baie de Seine orientale (France). Thèse Université de Rouen: 293pp.

Lambert, C., Jehanno, C., Silverberg, N., Brun-Cottan, J.C. and Chesselet, R., 1981. Lognormal distribution of suspended particles in the Ocean. 7. Marine Res., 39, 77-98.

McCammon, R. B., 1976a. An interactive computer graphics approach for dissecting a mixture of normal or lognormal distributions. In: Proc. 3rd Ann. Conf. on Computer Graphics, Interactive Techniques, and Image Processing, SIGGRAPH '76: Computer Graphics, 10, 8-12.

McCammon, R. B., 1976b. An interactive computer graphics program for dissecting a mixture of normal or lognormal distributions. In: Proc. 9th Interface Symp. on Computer Science and Statistics: Harvard Univ. and M.I.T., 36-44.

Saporta, G., 1990. Probabilités; analyse des données et statistique. Ed. Technip, Paris, 493pp.

Sinclair, A. J., 1974. Selection of threshold values in geochemical data using probability graphs. 7. Geochem. Explor., 3, 129-149.

Syvitski, J. P. M. and Murray, J. W., 1981. Particle interaction in fjord suspended sediment. Marine Geol., 39, 215-242.

Tennant C. B. and White M. L., 1959. Study of the distribution of some geochemical data. Econ. Geol., 54, 1281-1290.

Van Leussen, W., 1994. Estuarine macroflocs: their role in finegrained sediment transport. Universiteit Utrecht: 488pp. 